\title{
Bir sera işletmesi için şebekeye bağlı ve şebekeden bağımsız rüzgâr, fotovoltaik ve jeneratör sistemlerinin teknik ve ekonomik değerlendirmesi
}

\author{
Technical and economical evaluation of grid connected and stand-alone wind, \\ photovoltaic and generator systems for a greenhouse company
}

\author{
Nuri ÇAĞLAYANĐi \\ Akdeniz Üniversitesi, Mühendislik Fakültesi, Mekatronik Mühendisliği Bölümü, 07058 Antalya \\ Sorumlu yazar (Corresponding author): N. Çağlayan, e-posta (e-mail): nuricaglayan@akdeniz.edu.tr
}

MAKALE BILGISII

Alınıs tarihi 13 Mart 2019

Düzeltilme tarihi 27 Mayıs 2019

Kabul tarihi 02 Temmuz 2019

Anahtar Kelimeler:

Sera

Fotovoltaik Enerji

Modelleme

Enerji Maliyeti (EM)

Optimizasyon

\begin{abstract}
ÖZ
Bu çalıșmada, bir sera ișletmesinin elektrik ihtiyacının karșlanabilmesi için șebeke, rüzgâr $(\mathrm{RT})$, güneş $(\mathrm{FV})$ ve jeneratör enerji sistemlerinin modelleme ve bilgisayar benzetimleri yapılmıştır. Bilgisayar benzetiminde işletmenin elektrik yükü günlük $369.52 \mathrm{kWh}$ olarak tespit edilmiștir. Ayrıca bu sistemlerin ekonomik fizibilitesi birim enerji maliyetine (EM) göre değerlendirilmiştir. Benzetim (Simülasyon) sonuçlarına göre, fotovoltaik ve rüzgâr enerji sistemlerinin enerji maliyetleri sırasıyla 0.084 ve $0.059 \$ \mathrm{~kW}^{-1}$ olmaktadır. EM sonuçlarına göre, fotovoltaik sistem, rüzgâr enerji sistemine göre daha pahalıdır. Yıllık enerji üretim miktarları incelendiğinde ise, rüzgâr enerji sistemi fotovoltaik enerji sisteminden 3.1 kat daha fazla enerji üretebilmektedir. Öte yandan, dizel jeneratörün enerji maliyeti $\left(0.554 \$ \mathrm{kWh}^{-1}\right)$ fotovoltaik sistemle birlikte bu işletme için en pahalı enerji kaynağıdır. Çalışmada ayrıca zararlı gaz emisyon değerleri de araștırılmıștır. Rüzgâr enerji sistemi kurulursa, yılda $34742 \mathrm{~kg}$ $\mathrm{CO}_{2}, 151 \mathrm{~kg} \mathrm{SO}{ }_{2}$ ve $73.7 \mathrm{~kg} \mathrm{NO}_{\mathrm{x}}$ salınımı önlenebilecektir. Elde edilen sonuçlara göre sera işletmesi için en uygun sistemin rüzgâr enerjisi olduğu görülmüş̧ür.
\end{abstract}

ARTICLE INFO

Received 13 March 2019

Received in revised form 27 May 2019

Accepted 02 July 2019

\section{Keywords:}

Greenhouse

Photovoltaic Energy

Modelling

Cost of Energy (COE)

Optimization

\begin{abstract}
In this study, modeling and computer simulations were made by using grid, wind (WT), solar (PV) and generator energy systems in order to meet the electricity needs of a greenhouse company. In the computer simulation, the electrical load of the company was found as 369.52 $\mathrm{kWh}$ per day and optimization and sensitivity analyzes were performed for the most suitable system to meet this electric load. The results were evaluated according to the cost of energy (COE). According to the simulation results, the energy cost of photovoltaic and wind energy systems is 0.084 and $0.059 \$ \mathrm{~kW}^{-1}$, respectively. COE results show that the photovoltaic system is more expensive than the wind energy system. When the annual energy production amounts are examined, the wind energy system can produce 3.1 times more energy than the photovoltaic system. On the other hand, the energy cost of the diesel generator $\left(0.554 \$ \mathrm{kWh}^{-1}\right)$ is the most expensive energy source for this operation with the photovoltaic system. In the study, harmful gas emission values were also investigated. If a wind energy system is installed, $34742 \mathrm{~kg} \mathrm{CO}_{2}, 151 \mathrm{~kg} \mathrm{SO}_{2}$ and $73.7 \mathrm{~kg} \mathrm{NO}_{\mathrm{x}}$ emissions can be prevented annually. According to the results, it was found that the most suitable system for greenhouse operation was wind energy.
\end{abstract}

\section{Giriş}

Türkiye'nin 2017 yılı sonu itibarıla elektrik üretimi 295.5 milyar $\mathrm{kWh}$, tüketimi ise 294.9 milyar $\mathrm{kWh}$ olmuştur (BP 2019). Elektrik tüketiminin 2023 y1lında baz senaryoya göre yıllık ortalama \%4.8 artışla $385.10^{9} \quad$ kWh'e ulaşması beklenmektedir. Türkiye'deki elektrik üretiminin \%28.2'si doğal gaz, \%21.6's1 kömür, \%44.2'si yenilenebilir enerjilerden, $\% 5$ 'i ticari olmayan yakıtlardan ve \%0.4'ü akaryakıt gibi kaynaklar kullanılarak elde edilmiştir. Yenilenebilir enerji kaynaklarından üretilen elektrik enerjisinin \%7.7'si rüzgârdan ve $\% 1.7$ 'si ise güneş enerjisinden fotovoltaik (PV) ilkeye bağlı olarak üretilmektedir (ETKB 2019).

Türkiye, elektrik talebindeki hızlı büyüme ve fosil yakıtların tükenmesiyle birlikte, fosil yakıt rezervlerinin ömrünü uzatmak için yenilenebilir enerjinin önemini kavramış ve küresel iklim değişikliğiyle, özellikle de sera gazı salımlarıyla mücadelede 
sürdürülebilir çözümler getirmiştir. Enerji Piyasası Düzenleme Kurumu (EPDK)'nun 6446 say1l Elektrik Piyasas1 Kanunu'na göre, tüketiciler lisans alma veya şirket kurma yükümlülüğü olmaksızın, güneş, rüzgâr gibi yenilenebilir kaynaklardan ürettikleri $1 \mathrm{MW}$ güce kadar elektrik enerjisi üretebilecek ve ihtiyaç fazlasını dağıtım şebekesine satabileceklerdir. Türkiye'deki lisanssız üretim tesislerinin kurulu gücü 2017 yılı sonu itibariyle $3173.32 \mathrm{MW}$ güce ulaşmıştır. Belirtilen toplam enerji değerinin \%93.90'1 ile güneş santrallerine aittir. Güneş santrallerini sırasıyla $\% 2.71$ ile doğal gaz, $\% 2.10$ ile biyokütle ve \%1.01 ile de rüzgâr enerjisi tesisleri izlemiştir (EPDK 2017).

Maliyetlerin gün geçtikçe daha çok önem kazandığ 1 günümüz ekonomik şartlarında, enerji maliyetlerin sürekli artması, özellikle tarım işletmelerini tasarruf yapmaya ve mümkün olan en düşük fiyatla elektrik elde edebilecekleri çözüm yolları bulmaya zorlamaktadır. $\mathrm{Bu}$ amaçla, enerji kaynaklarını çeşitlendirmekle ilgilenen tarım işletmelerinin yenilenebilir enerji kaynaklarına yöneldikleri görülmektedir. Özellikle jeotermal kaynakların bulunduğu bölgelerde, sera işletmelerinin sayısında belirgin oranda artışlar gözlenmektedir. Öte yandan yenilenebilir enerji kaynaklarının kullanılmasına yönelik devlet teşviklerinin artmasıyla birlikte, çiftlik ve açık arazi sulaması için elektrik ihtiyacını karşılamak amacıyla güneşten fotovoltaik yöntemle üretilen elektrik kullanımı da giderek artmaktadır. Tarım işletmelerinin elektrik enerjisi ihtiyacını karşılama konusundaki beklentiler; enerjilerini güneş ve rüzgâr gibi yenilenebilir enerji kaynaklarından elde etmek, hatta üretecekleri fazla enerjiyi şebekeye satmaları yönündedir. Böylece, potansiyel yeşil elektriğin en yüksek elektrik talep dönemlerinde elektrik şebekesine satılarak, çevre kirletici maddelerin azaltılmasının yanı sıra, işletme maliyetlerinin düşürülmesine de önemli katkılar sağlanabilecektir.

Yenilenebilir enerji kaynağının kurulmasından önce fizibilite çalışması yapmak, yatırımın ekonomikliği konusunda fikir vermesi açısından oldukça önemlidir. Literatürde bazı tarım işletmelerinde elektrik ihtiyacının yenilenebilir enerji kaynakları ile karşılanabilmesine yönelik pek çok modelleme ve gerçek çalışmalar bulunmaktadır. Bu çalışmalarda bilgisayar benzetimlerine sıklıkla başvurulmakta, hızlı, güvenilir ve gerçeğe oldukça yakın sonuçlar elde edilebilmektedir. Bu amaçla kullanılan bilgisayar benzetim yazılımları arasında Amerika Ulusal Yenilenebilir Enerji Laboratuvarı (NREL: National Renewable Energy Laboratory) tarafindan geliştirilen HOMER (Hybrid Optimization Model for Electric Renewables) yaygın olarak kullanılmaktadır. HOMER yazılımı ile tek ve hibrit enerji sistemi modelleri geliştirilebilmektedir. Geliştirilen modeller sayesinde ilgili coğrafik bölge için en uygun maliyetli enerji sistemi tayin edebilmenin yanında, optimizasyon ve duyarlılık analizleri sonucunda hangi enerji sisteminin daha uygulanabilir olacağı belirlenebilmektedir (Ngan ve Tan 2012).

Byrne ve ark. (2005), bir tavuk çiftliğinde güneşten elektrik üretimi ve fizibilite çalışması yapmışlardır. Çalışmada, bilgisayar benzetimi modeli yaklaşımı ile alternatif senaryolar ve maliyet koşullarını değerlendirilmiştir. Çalışma sonuçlarına göre, güneşten elektrik üreten toplam $1.5 \mathrm{~kW}$ gücünde bir PV dizinin tavuk çiftliği için ekonomik olduğu ve sistemin kullanılmasiyla, 112 ton $\mathrm{CO}_{2}, 1.8$ ton $\mathrm{SO}_{2}$ ve 0.4 ton $\mathrm{NO}_{x}$ azaltılabileceği öngörülmüştür.

Türkdoğan ve ark. (2018), bilgisayar benzetimi kullanarak bir çiftlik evi ve 50 büyükbaş hayvanın yaşayabileceği bir barınağın elektriksel yük ihtiyacını karşılamak üzere şebekeden bağımsız hibrit enerji sisteminin teknik ve ekonomik açıdan uygulanabilirliğini araştırmışlardır. Çiftlik evinin elektriksel yük ihtiyacı hesaplanmış, rüzgâr hızı ve güneş radyasyon verileri kullanılarak, HOMER yazılımı ile hibrit enerji sistemi modeli oluşturulmuştur. Modellenen enerji sisteminde kurşun asit ve lityum iyon akü grupları kullanılmış, teknik ve ekonomik açıdan karşılaş̧ırma yapılmıştır. Elde edilen sonuçlara göre, birim enerji maliyeti ve teknik açıdan lityum iyon akü grubunun kullanıldığı hibrit enerji sisteminin daha uygulanabilir olduğu tespit edilmiştir.

Tudorache ve Morega (2008), jeneratör destekli fotovoltaik ve rüzgâr enerji sistemlerinin güç üretiminde en ekonomik sistem mimarisinin elde edilmesine yönelik modelleme ve bilgisayar benzetimleri yapmışlardır. Sistemlerin eş zamanlı çalıșması göz önüne alınarak yapılan çalıșmada, en ucuz elektrik maliyetinin, bir dizel jeneratör, dört fotovoltaik modül, iki rüzgâr türbini ve sekiz bataryadan oluşan sistem ile elde edileceği sonucuna ulaşmışlardır.

Himri ve ark. (2008), Cezayir'in güney batısında bulunan bir bölgede şebeke bağlantısı olmayan hibrid enerji sistemleri için teknik ve ekonomik bir değerlendirme gerçekleştirmişlerdir. Yapılan çalı̧̧mada enerji üretiminin, yaşam döngüsü maliyetlerinin ve sera gazı emisyonlarının düşürülmesi için en uygun enerji sistemi modellenmiştir. Araştırmacılar, $5 \mathrm{~m} \mathrm{~s}^{-1}$ den daha düşük rüzgâr hızları için simülasyonda kullanılan dizel yakıt fiyatı aralığ mevcut dizel enerji santralinin uygun tek çözüm olduğu sonucuna varmışlardır. Öte yandan, dizel yakıt fiyatının $\geq 0.162 \$ 1^{-1}$ ve rüzgâr hızının $\geq 5.48 \mathrm{~m} \mathrm{~s}^{-1}$ olduğu durumda da rüzgâr -dizel hibrid enerji sisteminin daha uygun bir çözüm olduğunu sonucuna ulaşmışlardır (OECD 2016).

Dalton ve ark. (2008), yaptıkları yenilenebilir enerji modellemesinde, büyük ölçekli şebeke bağlantılı uygulamalar için fotovoltaik sistemler yerine rüzgâr enerjisi dönüşüm sistemlerinin ekonomik bakımdan daha uygulanabilir olduğu belirlenmiştir. Alternatif bir uygulama olan hidrojen yakıt hücrelerinin kullanımının ve hidrojen depolamanın şebeke bağlantılı sistemlerde ekonomik olmadığ 1 sonucuna varmışlardır.

Yapılan çalışmada da bir sera işletmesinin elektrik yükünün güneş, rüzgâr ve jeneratör güç sistemleriyle karşılanabilme olanakları incelenmiş, önerilen sistemler için bilgisayar modellemesi, benzetim ve optimizasyon araçları kullanılarak teknik ve ekonomik değerlendirmeler yapılmıştır.

\section{Materyal ve Yöntem}

\subsection{Modelleme ve bilgisayar benzetimleri}

Çalışma kapsamında elektrik yükü incelenen sera işletmesi Sandıklı (Afyonkarahisar) ilçesi sınırları $\left(38.27^{\circ} \mathrm{N} ; 30.16^{\circ} \mathrm{E}\right)$ içerisinde bulunmaktadır. İşletme, işletme binası, 1sıtma merkezi ve toplam 15 da sera alanına sahiptir. Sera, gotik çatılı, oluk altı yüksekliği $4.5 \mathrm{~m}$ ve tünel açıklığı $9.6 \mathrm{~m}$ 'dir. Yan duvarları çift plastik ile örtülü olan serada 1 sı perdesi bulunmakta ve jeotermal enerji kullanılarak 1sitma yapılmaktadır. Topraksız tarım yapılan tesiste yıl boyu kesintisiz faaliyet sürdürülmektedir.

Çalışmada işletme için şebeke bağlantılı (Grid connected) ve şebeke bağlantısız (Stand-alone) hibrit enerji sistemleri modellenmiştir. Şebeke bağlantısı olan sistemlerde (Şekil $1 \mathrm{a}, \mathrm{b}$ ve c); şebeke ile birlikte rüzgâr türbini (RT), fotovoltaik (FV) ve $(\mathrm{FV}+\mathrm{RT})$ enerji sistemleri, şebeke bağlantısı olmayan sistemlerde (Şekil $1 \mathrm{~d}$, e, f ve g); her biri yalnız olmak üzere RT, $\mathrm{FV}, \mathrm{RT}+\mathrm{FV}$ ve jeneratör kullanılarak modellenmiştir. Tüm 
modellerde kurşun asid (LA) ve lityum iyon (LI) akü grubu kullanılmış ve farkları incelenmiştir. Modelleme ve bilgisayar benzetimlerinde veri girişi olarak, işletmenin bulunduğu Sandıklı'nın güneş 1şınımı, açıklık indeksi, güneşlenme süreleri, sıcaklık ve rüzgâr hızı verileri (Şekil 2 a, b, c ve d) kullanılmıştır. Bu veriler, NASA Yüzey Meteorolojisi ve Güneş Enerjisi veri tabanındaki 22 yıllık ortalama aylık verilerden elde edilmiştir (NASA 2019).
Bilgisayar benzetimlerinde farklı girdi değerleri kullanılarak belirli sınır koşullarının değiştirilmesiyle farklı durumlar için kaynakların yeterliliğine, maliyet varyasyonlarına ve yük durumuna göre optimizasyon yapılmış ve en uygun yenilenebilir enerji temelli sistem tasarımı belirlenmeye çalışılmıştır. Sistemlerin analizlerinde, HOMER Pro (ver. 3.11) yazılımı kullanılmıştır (HOMER 2019). HOMER, benzetim, optimizasyon ve duyarlılık analizi olmak üzere üç temel görev gerçekleştirir. Benzetim işleminde, yılın her bir saati için belirli
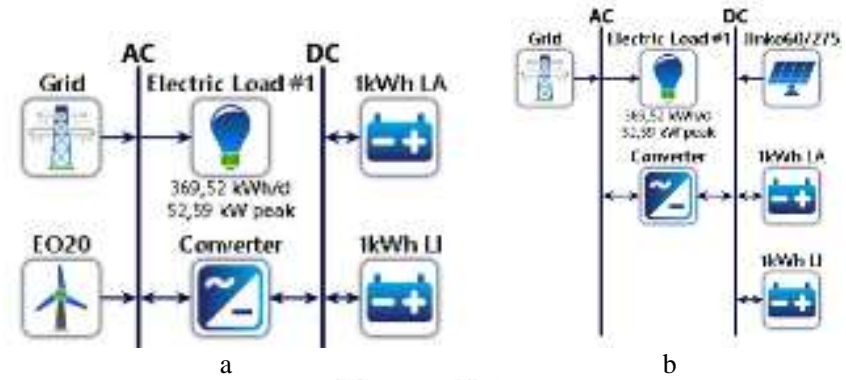

b

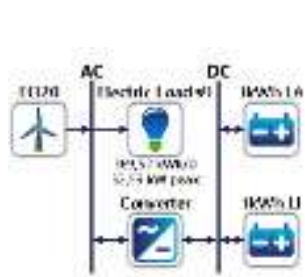

$\mathrm{d}$

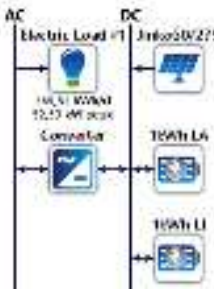

e

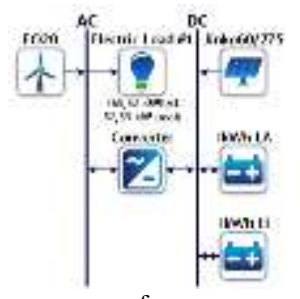

$\mathrm{f}$

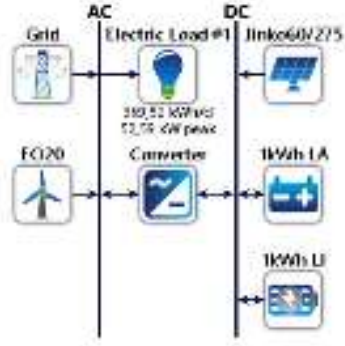

$\mathrm{c}$

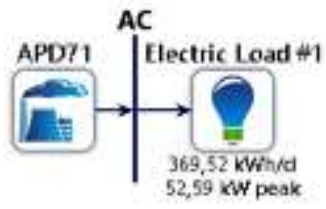

$\mathrm{g}$

Şekil 1. Şebeke bağlantılı sistemler: a. RT, b. FV ve c. FV+RT, şebeke bağlantısız sistemler: d. RT, e. FV, f. FV+RT ve g. Jeneratör.

Figure 1. Grid-connected systems: a. Wind türbine (WT), b. Photovoltaic (PV) and c. PV+WT, Stand-alone sytems: d. WT, e. PV, f. PV+WT ve g. Generator.
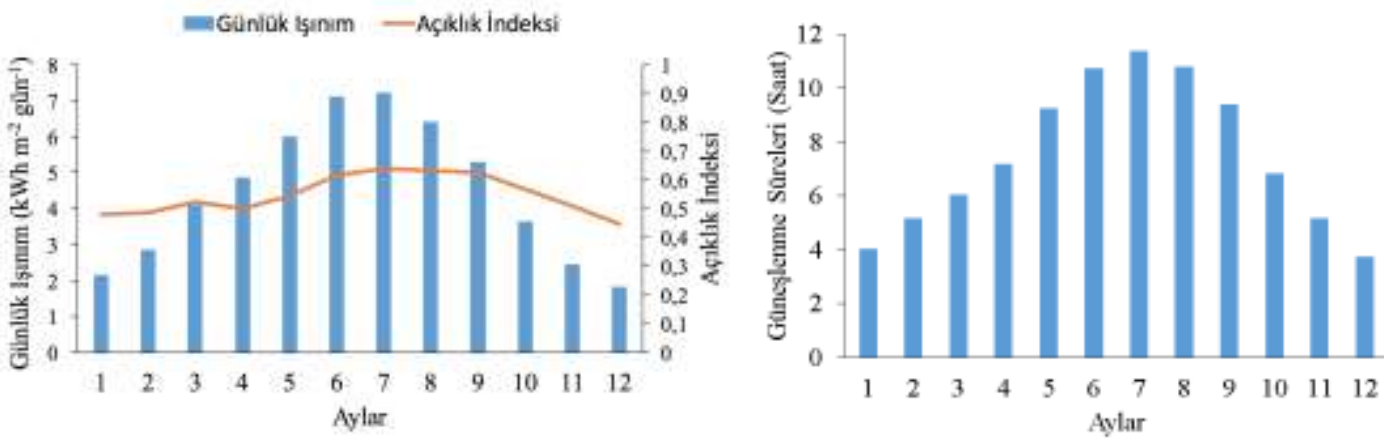

a
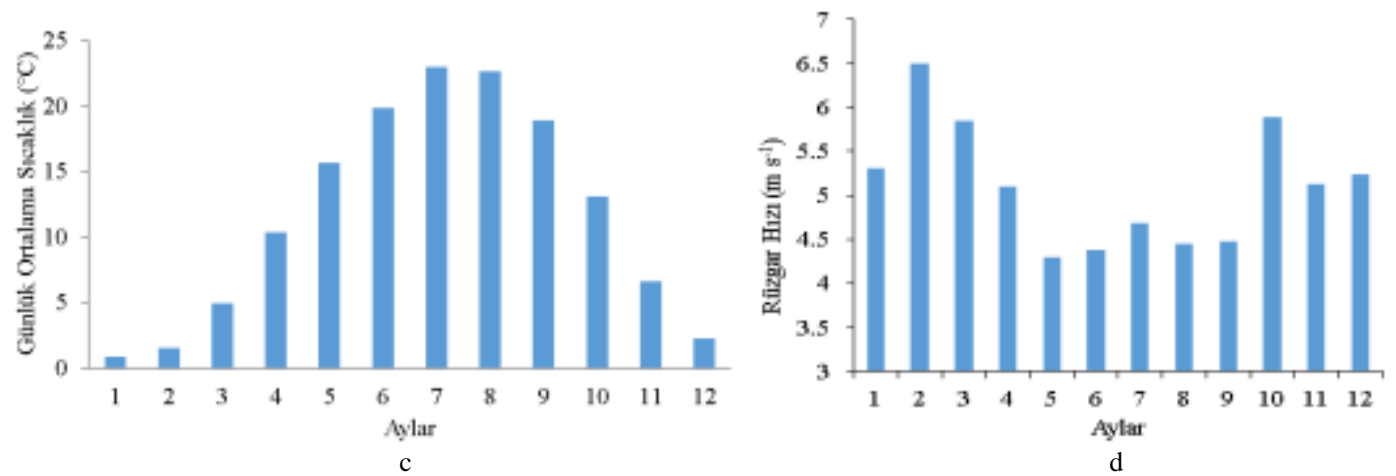

Şekil 2. a. Günlük ışınım ve açıklık indeksi, b. Güneşlenme süreleri, c. Sıcaklık ve d. Aylık ortalama rüzgâr hızı değerleri.

Figure 2. a. The values of daily radiation and clearness index, b. Sunshine duration, c. Temperature and d. Average monthly wind speed. 
bir mikro enerji sistem yapılandırmasının performansı, sistemin teknik fizibilitesi ve yaşam döngüsü maliyetini belirleyebilmek için modellenir. Optimizasyon işleminde, en düşük yaşam döngüsü maliyetini elde edebilmek ve teknik kısıtlamaları karşılayan en uygun sistem mimarisini yakalayabilmek için birçok farklı sistem mimarisinin benzetimi sağlanmaktadır. Sistemi oluşturan elemanların kombinasyonu ve bu elemanların her birinin büyüklüğü veya niceliği gibi sistem tasarımcısının kontrolündeki değişkenlerin en uygun değerini belirlemektedir. Duyarlılık analizi işleminde ise, model girişlerindeki değişikliklerin veya belirsizliklerin etkilerini ölçmek için bir giriş varsayımları dizisi altında çok sayıda optimizasyon işlemi gerçekleştirilmektedir. Ortalama rüzgâr hızı, ışınım değeri veya gelecekteki yakıt fiyatı gibi tasarımcının kontrolü dışındaki değişkenlerin veya belirsizliklerin etkilerinin değerlendirilmesinde önemli rol oynar (Lalwani 2010).

\subsection{Modelleme parametreleri}

Bilgisayar benzetimlerinde birinci aşamada işletmenin günlük elektrik yük miktarı ve yıl içindeki görünüşü incelenmiştir. İkinci aşamada ise önerilen sistemleri oluşturan ekipmanların kapasite ve maliyet değerleri (Çizelge 1) göz önüne alınarak, sistemlerin teknik ve ekonomik fizibilitesi için benzetim çalışmaları yapılmıştır. Benzetim aracının optimizasyon özelliği kullanılarak, yükü karşılayabilecek en uygun enerji sistemlerinin net bugünkü değerleri (NBD) ve enerji maliyetleri (EM) gibi ekonomik göstergeleri elde edilmiştir. Duyarlılık analizlerinde, güneş ışınımı, rüzgâr hızı ve sıcaklık için iki değişim durumu göz önüne alınırken, dizel yakıt için üç farklı yakıt fiyatının olması durumu göz önüne alınmıştır. Buna göre, güneş ışınımı; 4.49 ve $7 \mathrm{kWh} \mathrm{m}^{-2}$ gün$^{-1}$, rüzgâr hızı; 5.10 ve $6.50 \mathrm{~m} \mathrm{~s}^{-1}$, sıcaklık; 11.63 ve $25^{\circ} \mathrm{C}$ ve dizel yakıt fiyatı; $0.50,1.19$ ve $1.50 \$ \mathrm{l}^{-1}$ değişimlerine göre hesaplamalar yapılmıştır.

\subsection{1. İşletmenin elektrik yükü}

İşletmenin yük dağılımı tespitinde, serada kullanılan havalandirma, sulama, 1sitma sistemindeki elektrikli makine ve cihazların elektrik güçleri, günlük kullanım süreleri hakkında bilgi alınmış ve aylık elektrik faturaları üzerinden kıyaslamalar yapılarak veriler toplanmıştır. İşletmenin elektriksel yükünün dağılımına bakıldığında, işletme binasının \%13, ısıtma sisteminin \%39, sulama ve havalandırma sistemlerinin ise \%24'er paya sahip oldukları hesaplanmıştır.

Yük verileri, günlük elektrik tüketiminin $369.52 \mathrm{kWh}$, en yüksek güç talebinin $52.59 \mathrm{~kW}$ olduğunu göstermiştir. İşletmenin yıllık elektrik yükü görünüşü Şekil 3'de verilmiştir.

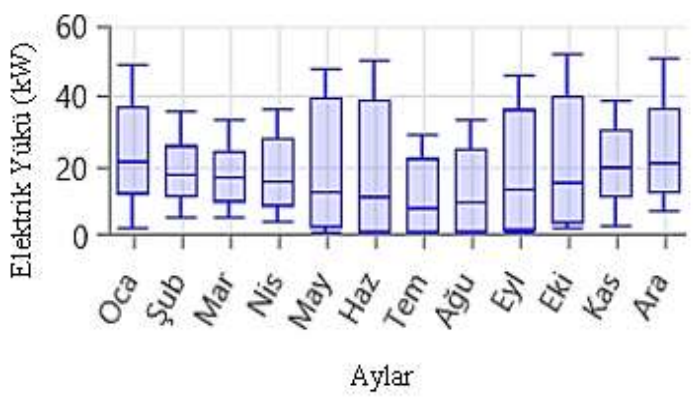

Şekil 3. İşletmenin yıllık elektrik yükü görünüşü.

Figure 3. Annual electricity load profil of the greenhouse company.

\subsubsection{Güneş enerjisi (FV: fotovoltaik) sistemi}

Fotovoltaik modül, yüzeylerine gelen güneş 1şı̆̆ını doğrudan elektrik enerjisine (Doğru akım) dönüştüren yariiletken malzemelerden üretilmektedir. Güneş enerjisi, PV hücrenin yapısına bağlı olarak \%5 ila \%20 arasında bir verimle elektrik enerjisine çevrilebilir. Güç çıkışını artırmak amacıyla yüzeylerine dik ışın gelecek şekilde çok sayıda güneş modülü eğimli yüzey üzerine monte edilir ve elektriksel olarak birbirine paralel-seri bağlanarak MW seviyesindeki güçlere kadar fotovoltaik elektrik üretim santralleri oluşturulabilir. Bir FV dizisinin ürettiği güç Eşitlik 1 ile hesaplanabilir (HOMER 2019):

$$
P_{P V}=Y_{P V} f_{P V}\left(\frac{\bar{G}_{T}}{\bar{G}_{T, S T C}}\right)\left[1+\alpha_{P}\left(T_{c}-T_{c, S T C}\right)\right]
$$

Burada, $Y_{P V} \mathrm{FV}$ dizisinin toplam kurulu gücünü, $f_{P V}$ bozulma faktörünü, $G_{T} \mathrm{FV}$ yüzeyine gelen solar 1 şınımı $\left(\mathrm{kW} \mathrm{m}^{-2}\right), G_{T, S T C}$ standart test koşullarındaki ışınımı $\left(1 \mathrm{~kW} \mathrm{~m}^{-2}\right), \alpha_{p} \mathrm{FV}$ sıcaklık katsayısını $\left(\%{ }^{\circ} \mathrm{C}^{-1}\right), T_{c} \mathrm{FV}$ hücre sicaklığını ve $T_{c}$, STC standart test koşullarındaki hücre sıcaklığını $\left(25^{\circ} \mathrm{C}\right)$ göstermektedir. Güneş modüllerinin kullanıldığ1 benzetimlerde, Şekil 2'de verilen güneş 1şınımı ve sıcaklık değerleri esas alınmıştır. Modelleme ve bilgisayar benzetimlerinde $275 \mathrm{~W}$ gücünde ve $\% 16.80$ verimle çalışan polikristal silikon fotovoltaik modüller (JINKO Solar 2019) kullanılmıştır.

\subsubsection{Rüzgâr enerjisi (RT: rüzgâr türbini) sistemi}

Yapılan modellemelerde $20 \mathrm{~kW}$ gücünde, kule yükssekliği $36 \mathrm{~m}$ olan 3 kanatlı rüzgâr türbinleri (Eocycle Inc. 2019) kullanılmıştır. Türbinlerin kullanıldığı benzetimlerde, Şekil 1 d'de verilen rüzgâr hızı ortalama değerleri esas alınmıştır.

Çizelge 1. Sistem ekipmanlarının maliyet değerleri.

Table 1. Cost values of system equipment.

\begin{tabular}{|c|c|c|c|c|c|c|}
\hline \multirow{2}{*}{ Ekipman } & \multicolumn{2}{|c|}{ Yatırım Maliyeti } & \multicolumn{2}{|c|}{ Değiştirme Maliyeti } & \multirow{2}{*}{$\begin{array}{c}\text { İşletme Maliyeti } \\
\left(\$ \text { yll }^{-1}\right)\end{array}$} & \multirow{2}{*}{$\begin{array}{c}\text { Ömür } \\
(\mathrm{yll})\end{array}$} \\
\hline & $\left(\$ \mathbf{k W}^{-1}\right)$ & $\left(\$\right.$ Adet $\left.^{-1}\right)$ & $\left(\$ \mathbf{k W}^{-1}\right)$ & $\left(\$\right.$ Adet $\left.^{-1}\right)$ & & \\
\hline FV & 4500 & & 2500 & & 50 & 25 \\
\hline RT & & 33200 & & 33200 & 1000 & 20 \\
\hline Dönüștürücü & 115 & & 115 & & 0 & 15 \\
\hline Jeneratör & 200 & & 200 & & $0.03 \$ \mathrm{~h}^{-1}$ & $15000 \mathrm{~h}$ \\
\hline LA Akü & & 300 & & 300 & 10 & 10 \\
\hline LI Akü & & 550 & & 550 & 10 & 15 \\
\hline
\end{tabular}

FV: Fotovoltaik panel, RT: Rüzgâr türbini, LA: Kurşun asit akü; LI: Lityum iyon akü. 


\subsubsection{Dizel jeneratör}

Modellemelerde $3 \mathrm{faz}, 71 \mathrm{kVA}(56.80 \mathrm{~kW})$ gücünde bir dizel jeneratör kullanılmıştır (AKSA 2019). Jeneratörün verimi, çıkış güç değeri ile logaritmik olarak artmaktadır. Dizel jeneratörlerde $\mathrm{kW}$ başına maliyet değeri daha düşük güçlü kapasitedeki jeneratörler için daha yüksektir. Elde edilen bilgisayar benzetim sonuçlarında jeneratörün her litre yakıt tüketimi başına açığa çıkarttığı toplam karbon emisyonu da belirlenmiştir.

\subsubsection{Akü grubu}

Akü gurubu seri ve paralel bağlı akülerden oluşan yedekleme sistemi olarak kullanılmakta ve yük boyunca gerilim değerini sabit tutmaktadır. Modellemelerde, $12 \mathrm{~V}, 83.4 \mathrm{Ah}$, $1 \mathrm{kWh}$ kurşun asit, (LA) ve $6 \mathrm{~V}, 167 \mathrm{Ah}, 1 \mathrm{kWh}$ lityum iyon, (LI) tip iki farklı akü grubu kullanılmıştır.

\subsubsection{Dönüştürücü}

Dönüştürücü (Converter), FV modüller ve akü grupları gibi doğru akım kaynaklarından elde edilen akımın alternatif akıma dönüştürülmesinde kullanılmaktadır. Dönüştürülen bu akım, sera işletmesinde kullanılan motor, kompresör, pompa gibi elektrik makineleri için gerekli olan alternatif akım ihtiyacını karşılamaktadır. Bilgisayar benzetimlerinde \%95 verimli dönüştürücü kullanılmış, sistemde kullanılacak dönüştürücü gücü optimizasyon sonucunda belirlenmiştir.

\subsection{7. Şebeke bağlantısı}

Sera işletmeleri, tarımsal sulama için belirlenen tarifeye göre, şebekeden elektrik satın almaktadırlar. İşletmenin elektrik enerjisi aldığı firma ile $150 \quad \mathrm{~kW}$ güç sözleşmelidir. Modellemelerde elektriğin birim fiyatı $0.12 \$ \mathrm{kWh}^{-1}$ olarak alınmış ve 2013 yılında EPDK tarafından yayınlanan lisanssız enerji üretimi yönetmeliğine (EPDK 2013) göre ihtiyaç fazlası enerji satılarak işletmeye gelir sağlanabileceği varsayılmıştır. $\mathrm{Bu}$ amaçla modellemelerde EPDK'nın belirlediği, fotovoltaik enerji satışı için $0.133 \$ \mathrm{kWh}^{-1}$, rüzgârdan üretilen enerji satış1 için ise $0.073 \$ \mathrm{kWh}^{-1}$ verileri kullanılmıştır.

\subsection{Ekonomik analiz}

\subsubsection{Ekonomik göstergeler}

Bilgisayar benzetimlerinde kullanılan kazanç oranı y1llık faiz oranıdır. Bu oran anlık maliyetler ile yıllık hale getirilmiş maliyetler arasındaki dönüşümü sağlamak için kullanılan indirim oranıdır ve Eşitlik 2'de verildiği gibi net nominal faiz oranına bağlıdır (Yılmaz 2008).

$$
i=\frac{i^{\prime}-f}{1+f}
$$

Burada, $i$ gerçek faiz oranı, $i^{\prime}$ net nominal faiz oranı ve $f$ yıllık enflasyon oranıdır. Türkiye için, ${ }^{l}=\% 22.50$ ve $f=\% 18.49$ kullanılmıştır (2019 yılı Mart ayı verileri esas alınmıştır) (TCMB 2019). Bu durumda gerçek faiz oranı \%3.38 olarak bulunmuştur. Öte yandan jeneratör için kullanılacak dizel yakıtın litre fiyatı 1.19 \$ olarak alınmış (PO 2019) ve ayrıca yakıt fiyatının 0.5 ve $1.5 \$ \mathrm{l}^{-1}$ olması durumunda da duyarlılık analizleri yapılmıştır.

\subsubsection{Net bugünkü değer (NBD)}

Bir yatırımın net bugünkü değeri (NBD), yatırımın ekonomik ömrü boyunca sağladığı getirinin bugünkü değerinden yatırım giderlerinin bugünkü değerinin düşülmesi ile elde edilen farkı ifade eder. $\mathrm{Bu}$ fark pozitif $(N B D>0)$ ise proje kabul edilir. Eğer $N B D=0$ olursa yıllık hâsılat akımlarının işletme maliyetlerini ve yıllık yatırım maliyetlerini anca karşıladığı anlaşılır. NBD Eşitlik 3 yardımıyla hesaplanabilir (Sarıaslan 1990).

$$
N B D=\sum_{t=0}^{n} \frac{B_{t}}{(1+i)^{t}}-\sum_{t=0}^{n} \frac{C_{t}}{(1+i)^{t}}
$$

Burada, $B_{t} t$ yılındaki nakit girişi; $C_{t} t$ yılındaki nakit çıkışı, $n$ yildır.

\subsubsection{Enerji maliyeti (EM)}

Sistem tarafindan üretilen enerjinin birim maliyeti aynı zamanda teknik ve ekonomik değerlendirme kriteri olarak da kullanılmakta ve toplam yıllık maliyetin y1llık üretim enerjisine bölünmesiyle hesaplanmaktadır (Eşitlik 4).

$$
C O E=\frac{C_{t o t}}{E_{t o t}}
$$

Burada $C_{t o t}$ sistemin tüm parçalarıyla birlikte yıllık toplam maliyeti $\left(\$ \mathrm{y}_{1}{ }^{-1}\right)$ ve $E_{\text {tot }}$ yıllık üretilen enerjiyi $\left(\mathrm{kWh} \mathrm{y}^{-1}{ }^{-1}\right)$ göstermektedir (Fakhim ve ark. 2017).

\section{Bulgular ve Tartışma}

\section{1. Şebeke bağlantılı sistemler}

Şebeke bağlantılı yenilenebilir enerji sistemlerinin teknik ve ekonomik analiz sonuçları Çizelge 2'de verilmiştir. Bilgisayar benzetimlerinde çevresel faktör girdisi olarak, 1şınım, rüzgâr hızı ve sıcaklık değerlerinin ortalama ve en yüksek değerleri kullanılmıştır. Bilgisayar benzetimlerinde bu değişkenler girdi olarak alınmış ve önerilen her sistem için EM değerleri sıralanmıştır. En uygun EM değeri, birim enerji maliyeti en düşük olan, kurulabilecek en ekonomik sistemi göstermektedir.

FV+RT sistemi için yapılan optimizasyon sıralamasında, ilk sırada yalnız RT sistemin yer aldığı (FV sistemin olmadığı) yapının yer aldığı görülmüştür. Bunun anlamı hibrit sistemin kurulması bu işletme için ekonomik değildir. Sıralamaya göre FV+RT seçeneği ancak dördüncü en uygun sistemdir. Optimizasyon sonuçlarından elde edilen önemli bir çıktı da EM değerinin hem RT hem de FV+RT sistemleri için aynı olmasıdır. $\mathrm{Bu}$ durum da FV+RT yerine yalnız RT sisteminin kurulması daha uygundur. Hibrit yapıda FV sistemden elde edilmesi düşünülen enerjinin şebekeden satın alınmasının daha ekonomik, enerji maliyetinin daha düşük olacağı sonucuna varılmıştır.

Tek olarak şebekeye bağlanacak FV sistemi, RT ve FV+RT enerji sistemleriyle karşılaştırıldığında ise, (Işınım ve rüzgâr hızının ortalama değerleri esas alındığında) EM değeri $(0.084$ $\left.\$ \mathrm{kWh}^{-1}\right)$ diğer sistemlerden $\left(0.059 \$ \mathrm{kWh}^{-1}\right)$ daha yüksektir. Enerji üretim miktarlarına bakıldığında, RT sistemi FV sisteminden 3.1 kat daha yüksek enerji üretebilmektedir. Ayrıca çevre şartları en yüksek değere (Işınım: $7 \mathrm{kWh} \mathrm{m}^{-2}$ gün$^{-1}$; rüzgâr hızı: $6.5 \mathrm{~m} \mathrm{~s}^{-1}$ ve sıcaklık: $25^{\circ} \mathrm{C}$ ) çıktığında ise, RT (ve FV+RT) 
sistemin EM değeri $0.045 \$ \mathrm{kWh}^{-1}$ seviyesine inmektedir. Bu değer, şebeke bağlantılı sistemler arasındaki en düşük enerji maliyetini göstermektedir. Tüm sistemler enerji maliyetleri açısından değerlendirildiğinde, şebeke bağlantılı sistemler arasındaki en ekonomik sistemin RT enerji sistemi olmaktadır. RT sistemi için nakit akışları Çizelge 3 ve 4'te, şebeke bağlantılı ve bağlantısız sistemler için yıllık maliyetler Çizelge 5'de verilmiștir.

Çizelge 2. Şebeke bağlantılı yenilenebilir enerji sistemlerinin teknik ve ekonomik analiz sonuçları.

Table 2. Technical and economic analysis results of grid-connected renewable energy systems.

\begin{tabular}{|c|c|c|c|c|}
\hline \multirow[b]{2}{*}{ Güneş 1şınımı (kWh m ${ }^{-2}$ gün$\left.^{-1}\right)$} & \multicolumn{2}{|c|}{ FV } & \multicolumn{2}{|c|}{ RT ve $(\mathrm{FV}+\mathrm{RT})$} \\
\hline & 4.49 & 7.00 & 4.49 & 7.00 \\
\hline Sicaklık $\left({ }^{\circ} \mathrm{C}\right)$ & 11.63 & 25.00 & 11.63 & 25.00 \\
\hline Rüzgâr hızı (m s-1) & 5.10 & 6.50 & 5.10 & 6.50 \\
\hline FV gücü $(\mathrm{kW})$ & 31.63 & 34.37 & & \\
\hline RT sayısı (Adet) & & & 3 & 2 \\
\hline Dönüştürücü gücü (kW) & 28.20 & 30.36 & & \\
\hline $\mathrm{EM}\left(\$ \mathrm{kWh}^{-1}\right)$ & 0.084 & 0.079 & 0.059 & 0.045 \\
\hline NBD $(\$)$ & 1177249 & 1102958 & 815770.40 & 632987.10 \\
\hline İşletme maliyeti $\left(\$ \mathrm{y}_{1} \mathrm{l}^{-1}\right)$ & 9982.30 & 9141.96 & 6929.60 & 5482.25 \\
\hline Yatırım maliyeti (\$) & 145584.70 & 158141.70 & 99600 & 66400 \\
\hline Yenilenebilir enerji oranı $(\%)$ & 33.18 & 40.99 & 59.24 & 65.95 \\
\hline Enerji üretimi $\left(\mathrm{kWh} \mathrm{y}^{-1} \mathrm{l}^{-1}\right)$ & 52402.77 & 67682.16 & 162563.30 & 149379.00 \\
\hline Şebekeden alınan enerji (kWh) & 90116.66 & 79593.80 & 54971.03 & 45921.68 \\
\hline Şebekeye verilen enerji (kWh) & 0.00 & 0.00 & 0.00 & 0.00 \\
\hline
\end{tabular}

Çizelge 3. Şebeke bağlantılı RT sistemi için nakit akışları (Bileşene göre).

Table 3. Cash Flow for the grid-connected WT system (by component).

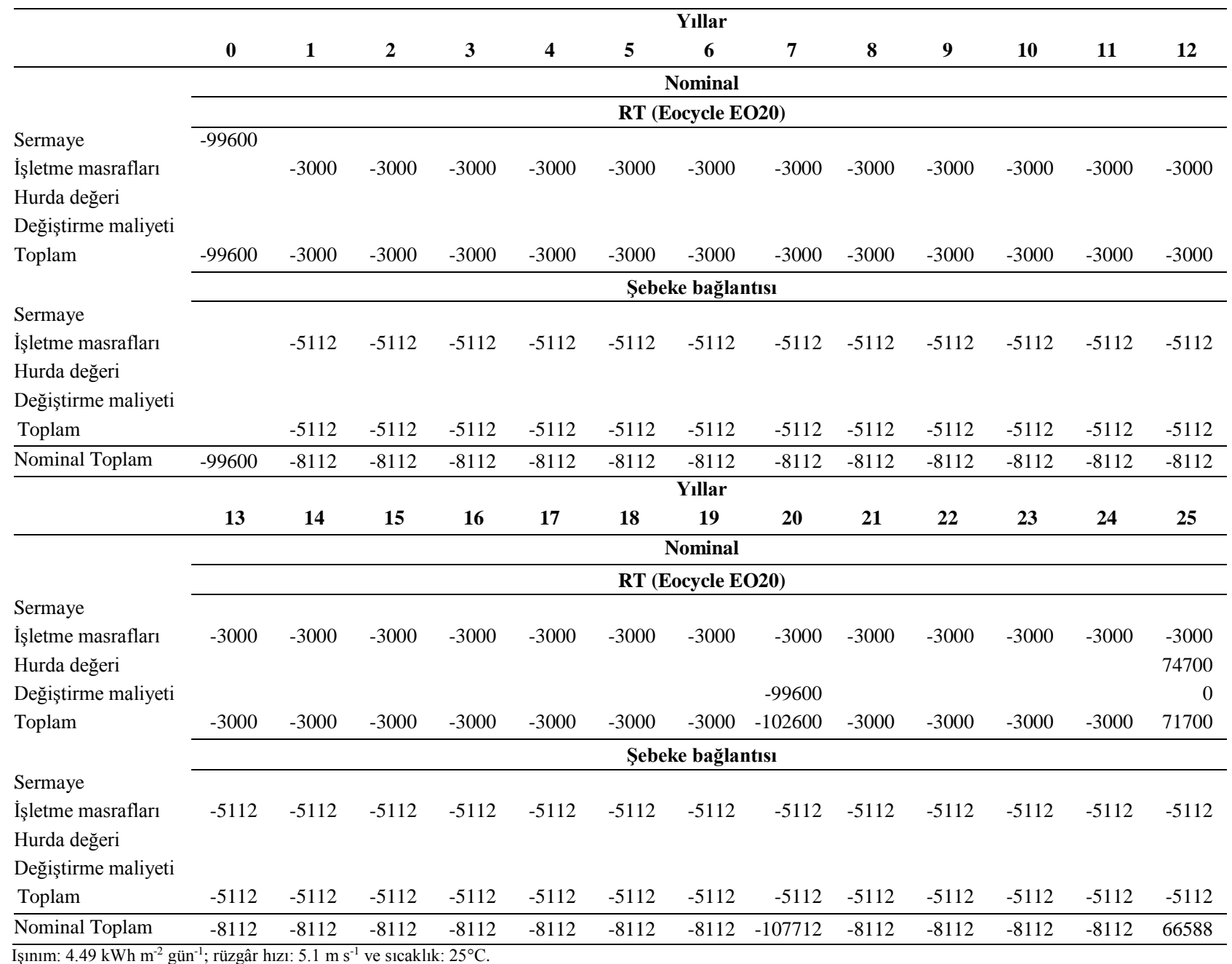


Çizelge 4. Şebeke bağlantısız RT sistemi için nakit akışları (Bileşene göre), (\$).

Table 4. Cash Flow for the stand-alone WT system (by component), (\$).

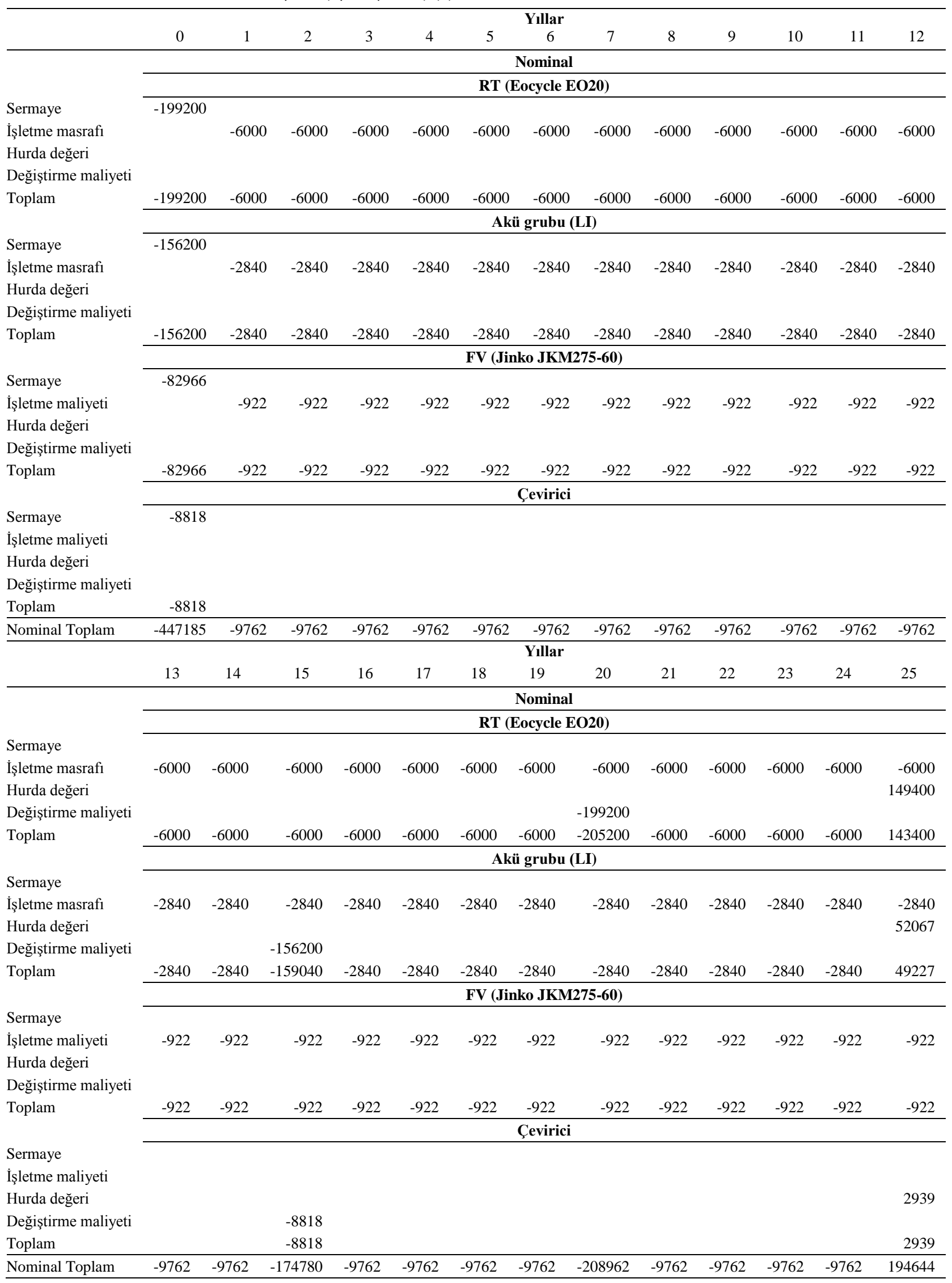


Çizelge 5. Şebeke bağlantılı ve bağlantısız sistemler için yıllık maliyetler (\$).

Table 5. Annualized costs for grid-connected and disconnected systems (\$).

\begin{tabular}{|c|c|c|c|c|c|c|}
\hline & Sermaye & İşletim masrafları & Değiştirme maliyeti & Hurda değeri & Finans kaynağı & Toplam \\
\hline \multicolumn{7}{|c|}{\begin{tabular}{|l} 
Şebeke bağlantılı sistem \\
\end{tabular}} \\
\hline RT & 963.72 & 3000 & 6153 & -7336 & & 2781 \\
\hline Şebeke & & 5112 & & & & 5112 \\
\hline Sistem & 963.72 & 8112 & 6153 & -7336 & & 7893 \\
\hline \multicolumn{7}{|c|}{ Şebeke bağlantısız sistem } \\
\hline RT & 2249 & 7000 & 14358 & -17117 & & 6489 \\
\hline Akü grubu & 1799 & 3380 & 7225 & -6086 & & 6318 \\
\hline Çevirici & 76.20 & & 306.07 & -257.80 & & 124.47 \\
\hline Sistem & 4124 & 10380 & 21889 & -23461 & & 12.932 \\
\hline
\end{tabular}

Şebeke bağlantılı önerilen sistemlerin optimizasyon çalışması sonucu elde edilen diğer sonuçlar şunlardır:

- İncelenen sistemlerde akü gruplarının kullanılması ekonomik görülmemektedir. $\mathrm{Bu}$ nedenle en uygun sistemlerin sıralandığı sonuçlarda akü bağlantısı bulunmamaktadir.

- İşletme için kurulabilecek sistemlerin hiçbirinden ihtiyaç fazlası enerji elde edilemeyecek ve şebekeye enerji satışı mümkün olamayacaktır.

- Şebeke dişında, işletmenin elektrik ihtiyacını karşılama oranlarına bakıldığında, FV sistemi \%36.8 ve RT sistemi $\% 74.7$ (Şekil 4 a ve b) olarak belirlenmiştir.

- Emisyon değerleri incelendiğinde, şebekeden elektrik alınmas1 yerine, RT sisteminin kurulması durumunda y1lda $34742 \mathrm{~kg} \mathrm{CO}, 151 \mathrm{~kg} \mathrm{SO}_{2}$ ve $73.7 \mathrm{~kg} \mathrm{NO}$, FV sisteminin kurulması durumunda ise yılda $56954 \mathrm{~kg} \mathrm{CO}$, $247 \mathrm{~kg} \mathrm{SO}_{2}$ ve $121 \mathrm{~kg} \mathrm{NO}_{x}$ salınım önlenebilecektir.

- Ekonomik analiz sonuçlarına göre, enflasyon oranının
\%18.49 iken iskonto edilmiş geri ödeme süresinin RT enerji sistemleri için 11.81 yıl olacağı, enflasyon değerinin $\% 10$ olması durumunda ise bu sürenin 9.08 y1la düşebileceği hesaplanmıştır.

\section{2. Şebekeye bağlı olmayan sistemler}

İşletmenin elektrik yükünün karşılanabilmesi için, şebekeye bağlı olmayan tek başına yenilenebilir enerji sistemi çözümleri Çizelge 6'da verilmiştir. Bu sistemler EM değerine göre incelendiğinde, işletme için en ekonomik sistemin (Ortalama 1şınım, rüzgâr hızı ve ortam sıcaklık verilerine göre) FV+RT ve RT sistemlerinde sirasiyla $0.098 \$ \mathrm{kWh}^{-1}$ ve $0.100 \$ \mathrm{kWh}^{-1}$ olduğu belirlenmiştir. FV sisteminin optimizasyon sonuçlarına bakıldığında ise, EM değerinin diğer sistemlerin yaklaşık üç katı olduğu bulunmuştur. Öte yandan işletme maliyetine bakıldığında, RT ve FV+RT birbirine yakın değerlerde olurken FV sisteminin işletme maliyeti bunların 2.5 katından fazla olmaktadır. Fakat FV sisteminin enerji üretiminin az farkla da olsa diğerlerinden daha yüksek olduğu görülmektedir.

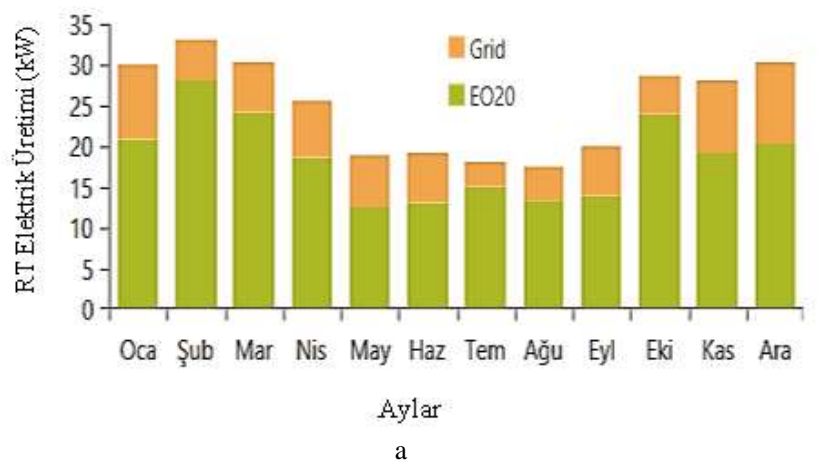

a

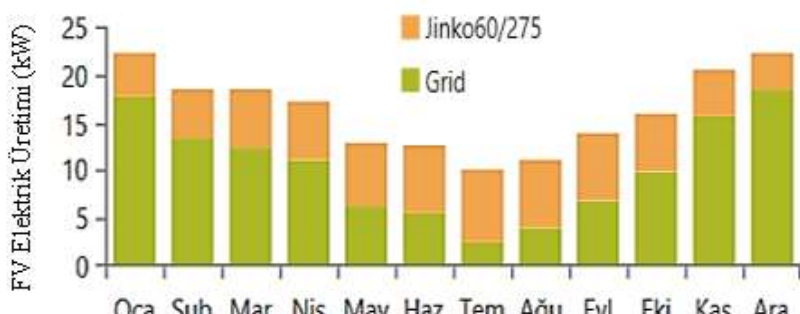

Aylar

b

Şekil 4. Şebeke bağlantılı a. RT ve b. FV enerji sistemlerinin aylık ortalama elektrik üretimleri.

Figure 4. Monthly average electricity energy production of grid-connected a. WT and b. PV systems. 
Önerilen şebeke bağlantısız sistemlerin optimizasyon çalışması sonucu elde edilen diğer sonuçlar şunlardır:

- Jeneratör sistemi hariç, diğer sistemlerde enerjinin depolanması için kurşun asit (LA) ve lityum iyon (LI) olmak akü grupları önerilmiştir. Benzetim sonuçlarına göre, en uygun akü grubunun LI akü grubu olduğu bulunmuştur. Öte yandan, otonomi süresi en yüksek akü grubu FV sisteme bağlı akü grubudur. Otonomi süresi, güneşli gün hiç olmasa dahi ihtiyaç olan enerjinin akülerden sağlanacağı süreyi göstermektedir. Analizlerde, FV sistemine bağl1 akülerin otonomi süresi 38.35 saat olarak tespit edilmiştir. Bu süre diğer sistemlere bağlı akülerin sahip olduğu otonomi süresinin iki katından fazladır. Bu önemli bir avantaj gibi görünse de birim enerji maliyetlerinin yüksek olması, FV sisteminin tercih edilmemesinin en önemli nedenidir.

- FV panellerinin ve rüzgâr türbinlerinin kapladıkları alana bakıldığında, bu işletme için sadece 7 adet rüzgâr türbini yeterli olduğu ve daha az yer kaplayacağı görülmektedir. Fakat etkin rüzgâr alabilmeleri için FV panellerinin aksine türbinlerin bir arada dizi şeklinde değil birbirlerinden daha uzak noktalara yerleştirilmesi gerekecektir.
Bilgisayar benzetim sonuçlarına göre, RT sistemindeki 7 türbinin en yüksek çıkış gücü toplam $129 \mathrm{~kW}$, ortalama güç $43.3 \mathrm{~kW}$ ve çalışma süresi yılda 6901 saat olarak elde edilmiştir.

- Tüm yükün dizel jeneratör tarafindan karşılanması durumunda en uygun jeneratör gücü $56.80 \mathrm{~kW}$ olarak bulunmuştur. Jeneratör güç sistemi EM değeri bakımından en pahalı enerji kaynağı olarak görülmektedir (Çizelge 6).

- Jeneratörün atmosfere y1lda $146191 \mathrm{~kg} \mathrm{CO} 2,995 \mathrm{~kg} \mathrm{CO}$, $358 \mathrm{~kg} \mathrm{SO} \mathrm{SO}_{2}$ ve $79.6 \mathrm{~kg} \mathrm{NO}_{\mathrm{x}}$ salımı olacağ 1 tespit edilmiştir. Fakat yenilenebilir enerji kaynaklarının yetersiz kaldığı ve şebekenin de olmadığı durumlarda, jeneratör tek enerji kaynağı olması bakımından işletmede bulundurulması önerilmektedir.

- Tüm sistemler için 25 yıl boyunca sürecek nakit akışları ve iskonto edilmiş geri ödeme süreleri incelendiğinde, RT, FV ve FV+RT sistemleri için sırasıyla, 8.86, 14.03 ve 9.03 yıl olacağı, dizel jeneratör için bu sürenin 25 yılın üzerinde çıkacağı öngörülmektedir.

Çizelge 6. Şebekeye bağlantısı olmayan enerji sistemlerinin teknik ve ekonomik analiz sonuçları.

Table 6. Technical and economic analysis results of stand-alone energy systems.

\begin{tabular}{|c|c|c|c|c|c|c|c|c|c|}
\hline & \multicolumn{2}{|c|}{ FV } & \multicolumn{2}{|c|}{ RT } & \multicolumn{2}{|c|}{ FV+RT } & \multicolumn{3}{|c|}{ JENERATÖR } \\
\hline & Durum 1 & Durum 2 & Durum 1 & Durum 2 & Durum 1 & Durum 2 & Durum 1 & Durum 2 & Durum 3 \\
\hline $\begin{array}{l}\text { Güneş 1şınımı } \\
\left(\mathrm{kWh} \mathrm{m}{ }^{-2} \text { gün }^{-1}\right)\end{array}$ & 4.49 & 7.00 & 4.49 & 7.00 & 4.49 & 7.00 & & & \\
\hline Sicaklık $\left({ }^{\circ} \mathrm{C}\right)$ & 11.63 & 25.00 & 11.63 & 25.00 & 11.63 & 25.00 & & & \\
\hline Rüzgâr hızı (m s s'-1) & 5.10 & 6.50 & 5.10 & 6.50 & 5.10 & 6.50 & & & \\
\hline Yakıt maliyeti $\left(\$ 1^{-1}\right)$ & & & & & & & 0.5 & 1.19 & 1.5 \\
\hline$\overline{\mathrm{FV} \text { güç }(\mathrm{kW})}$ & 248.58 & 133.10 & & & 18.44 & & & & \\
\hline RT sayısı (Adet) & & & 7 & 4 & 6 & 4 & & & \\
\hline \multicolumn{10}{|l|}{ LA akü sayısı (Adet) } \\
\hline LI akü sayısı (Adet) & 738 & 729 & 338 & 242 & 284 & 242 & & & \\
\hline Dönüştürücü gücü (kW) & 80.32 & 93.76 & 68.48 & 42.70 & 76.68 & 42.70 & & & \\
\hline $\mathrm{EM}(\$)$ & 0.286 & 0.202 & 0.100 & 0.064 & 0.098 & 0.064 & 0.361 & 0.647 & 0.775 \\
\hline $\mathrm{NBD}(\$)$ & 3844013 & 2712717 & 1336492 & 858767.9 & 1316142 & 858767.9 & 5032714 & 9018457 & 10809150 \\
\hline İşletme maliyeti $\left(\${\mathrm{y} 11^{-1}}^{-1}\right)$ & 22353.81 & 16468.76 & 8808.146 & 5689.026 & 8407.956 & 5689.026 & 48586.19 & 87151.91 & 104478.50 \\
\hline Yatırım maliyeti (\$) & 1533760 & 1010680 & 426175.2 & 270810.4 & 447184.7 & 270810.4 & & 11360 & \\
\hline $\begin{array}{l}\text { Yenilenebilir enerji oranı } \\
(\%)\end{array}$ & 100 & 100 & 100 & 100 & 100 & 100 & & & \\
\hline $\begin{array}{l}\text { FV enerji üretimi } \\
\left(\mathrm{kWh} \mathrm{y}^{-1}\right)^{-1}\end{array}$ & 411820.3 & 262126.8 & & & 30543.92 & & & & \\
\hline $\begin{array}{l}\text { RT enerji üretimi } \\
\left(\mathrm{kWh} \mathrm{yil}^{-1}\right)\end{array}$ & & & 379314.4 & 298758.1 & 325126.6 & 298758.1 & & & \\
\hline $\begin{array}{l}\text { Jeneratör enerji üretimi } \\
\left(\mathrm{kWh} \mathrm{yll}^{-1}\right)\end{array}$ & & & & & & & & 65857.80 & \\
\hline $\begin{array}{l}\text { Yillık bakım maliyeti } \\
\left(\$ \mathrm{y}_{1} \mathrm{l}^{-1}\right)\end{array}$ & & & 7000 & 4000 & 6000 & 4000 & & 4925.34 & \\
\hline LI akü otonomi süresi (h) & 38.35 & 37.88 & 17.56 & 12.57 & 14.76 & 12.57 & & & \\
\hline LI nominal kapasitesi (kWh) & 738.00 & 729.00 & 338.00 & 242.00 & 284.00 & 242.00 & & & \\
\hline Evirici çıkış gücü (kW) & 14.83 & 14.83 & 3.91 & 3.08 & 4.22 & 3.08 & & & \\
\hline Yakıt gideri $\left(\$ \mathrm{yll}^{-1}\right)$ & & & & & & & 27946.17 & 66511.89 & 83838.52 \\
\hline Yakıt tüketimi $\left(1{\left.\mathrm{y} 11^{-1}\right)}\right.$ & & & & & & & & 5892.34 & \\
\hline Jeneratör gücü (kW) & & & & & & & & 56.80 & \\
\hline
\end{tabular}




\section{Sonuçlar}

Bu çalışmada Afyonkarahisar ili Sandıklı İlçesi'nde faaliyet gösteren bir sera işletmesinin elektrik yükünün karşılanabilmesine yönelik modelleme ve bilgisayar benzetimleri yapılmıştır. Çalışmada, şebeke bağlantılı ve bağlantısız yenilenebilir enerji kaynakları ile jeneratör kullanılması durumlarına göre farklı sistem mimarileri incelenmiş ve işletme için teknik ve ekonomik fizibilite çalışması yapılmıştır. Uygun sistemler, EM değerlerine göre değerlendirilmiş ve sıralanmıştır. İlave olarak işletme için tercih edilebilecek en uygun sistemin geri ödeme süresi ve sera gazı emisyon değerleri de incelenmiştir. Elde edilen benzetim sonuçlarına göre şebeke bağlantılı ve şebekeden bağımsız çalışacak sistemlerin her ikisi için de rüzgâr enerjisi sisteminin daha ekonomik ve geri dönüş süresinin de daha kısa olacağı öngörülmektedir. Öte yandan FV sisteminin jeneratör sistemiyle birlikte enerji maliyeti bu işletme için en yüksek sistemler olduğu sonucuna ulaşılmıştır.

\section{Kaynaklar}

AKSA (2019) AKSA APD71A Jeneratör Teknik Dökümanı. https://www.aksa.com.tr/FrontProduct/CreatePDF/275. Erişim 20 Ocak 2019.

BP (2019) BP Energy Outlook. 2018 Edition. http://kojenturk.org/uploads/dokumanlar/bp-energy-outlook2018.pdf. Erişim 15 Ocak 2019.

Byrne J, Glover L, Hegedus S, VanWicklen G (2005) The potential of solar electric applications for Delaware's poultry farms. Final Report. Center for Energy and Environmental Policy, University of Delaware, State of Delaware.

Dalton GJ, Lockington DA, Baldock TE (2008) Feasibility analysis of stand-alone renewable energy supply options for a large hotel. Renewable Energy, Vol. 33, no. 7, pp. 1475-1490.

Eocycle Inc. (2019) EO20 Rüzgâr Türbini Teknik Dokümanı. https://eocycle.com/small-wind-turbine/. Erişim 10 Şubat 2019.

EPDK (2013) Elektrik Piyasasında Lisanssız Elektrik Üretimine İlişkin Yönetmelik https://www.epdk.org.tr/Detay/Icerik/3-0-049/yonetmelikler. Erişim: 21 Ocak 2019.

EPDK (2017) Elektrik Piyasası Gelişim Raporu. T.C. Enerji Piyasası Düzenleme Kurumu. http://www.epdk.org.tr/Detay/Icerik/3-0167/resmi-istatistikler. Erişim 25 Şubat 2019.

ETKB (2019) T.C. Enerji ve Tabii Kaynaklar Bakanlığı https://www.enerji.gov.tr/tr-TR/Sayfalar/Elektrik. Erişim 25 Şubat 2019.
Fakhim HA, Sarir MF (2017) Economic feasibility of power supply using hybrid system for a Hotel in cold climate, Int. J. Energy Econ. Pol. 7(2): 255-261.

Himri Y, Stambouli AB, Draoui B, Himri S (2008) Techno-economical study of hybrid power system for a remote village in Algeria. Energy 33: 1128-1136.

HOMER (2019) HOMER Pro Software Getting Started Guide. National Renewable Energy Laboratory, U.S. Department of Energy.

JINKO Solar (2019) JKM275-60 255-275 panel Teknik Dökümanı. https://www.jinkosolar.com/ftp/EN-JKM275P-60(4BB)-tr.pdf. Erişim 10 Ocak 2019.

Lalwani M, Kothari DP, Singh M (2010) Investigation of solar photovoltaic simulation softwares. Int. J Appl Eng Res 1: 585-601.

NASA (2019) Nasa Surface meteorology and Solar Energy Database. https://power.larc.nasa.gov/. Erişim 10 Ocak 2019.

Ngan MS, Tan CW (2012) Assessment of economic viability for PV/wind/diesel hybrid enegry system in southern Peninsular Malaysia. Renewable and Sustainable Energy Reviews 16(1): 634647.

OECD (2016) Factbook 2015-2016 Economic, Environmental and Social Statistics. http://www.oecd.org/publications/oecd-factbook18147364.htm. Erişim: 17 Şubat 2019.

PO (2019) Petrol Ofisi Dizel Yakıt Fiyatları. https://www.petrolofisi.com.tr/akaryakit-fiyatlari. Erişim 06 Mart 2019.

Sarıaslan H (1990) Yatırım Projelerinin Hazırlanması ve Değerlendirilmesi, Planlama-Analiz-Fizibilite, Turhan Kitapevi, Ankara, s. 240.

TCMB (2019) T.C. Merkez Bankası Enflasyon Verileri. https://www.tcmb.gov.tr/wps/wcm/connect/TR/TCMB+TR/Main+ Menu/Istatistikler/Enflasyon+Verileri. Erişim 10 Mart 2019.

Tudorache T, Morega A (2008) Optimum Design of Wind/PV/Diesel/Batteries Hybrid Systems, International Conference on Modern Power Systems, Cluj-Napoca, Romania, 1214 November, pp. 261-264.

Türkdoğan S, Dilber S, Çam B (2018) Hibrit Enerji Sistemlerinin Şebekeden Bağımsız Bir Çiftlik Evinde Uygulanabilirliğinin Ekonomik ve Teknik Açıdan İncelenmesi. Sinop Üniversitesi Fen Bilimleri Dergisi 3(2): 52-65.

Yılmaz U (2008) Gökçeada'da Yenilenebilir Enerji Kaynakları ile Elektrik Üretimi, Yüksek Lisans Tezi, İstanbul Teknik Üniversitesi Fen Bilimleri Enstitüsü, İstanbul. 